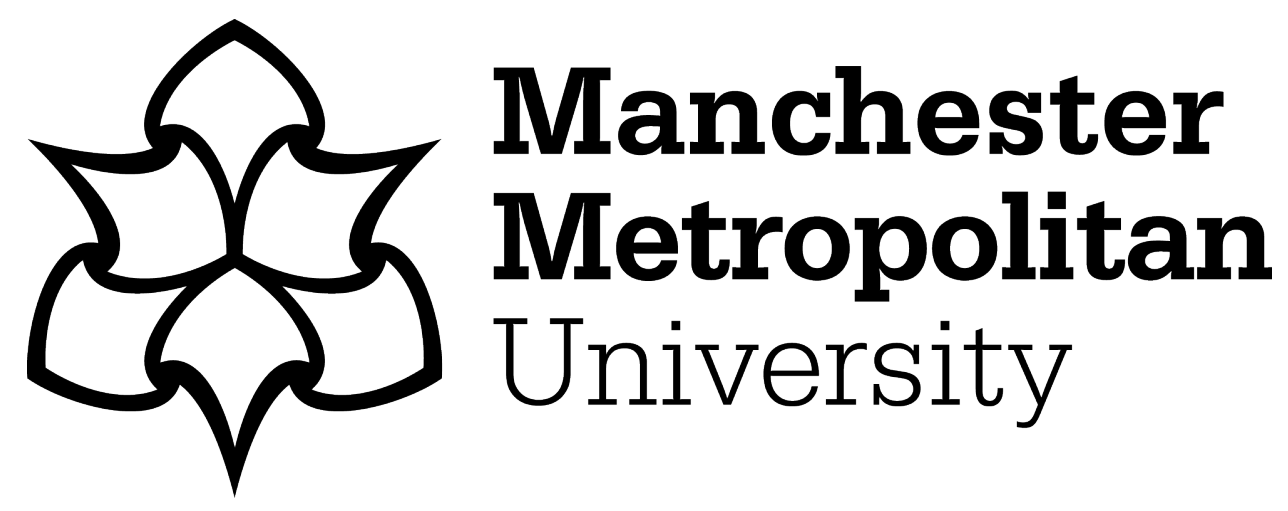

Sellar, S ORCID logoORCID: https://orcid.org/0000-0002-2840-5021 (2019) Making network markets in education: the development of data infrastructure in Australian schooling. Globalisation, Societies and Education, 15 (3). pp. 341-351. ISSN 1476-7724

Downloaded from: https://e-space.mmu.ac.uk/623372/

Version: Accepted Version

Publisher: Taylor \& Francis

DOI: https://doi.org/10.1080/14767724.2017.1330137

Please cite the published version 


\title{
Making network markets in education: The development of data infrastructure in Australian schooling
}

\begin{abstract}
This paper examines the development of data infrastructure in Australian schooling as a case study of making markets through standardisation. The recent growth of the education technology market and the longstanding agenda to develop interoperability standards for the information systems used by schools and jurisdictions are reviewed. A conceptual framework is then introduced that combines insights from infrastructure studies with the economic sociology literature that defines markets as devices that coordinate calculative agencies. Standardisation is an important element in the performance of markets because it disentangles and frames goods and agents. The paper then examines the case of the Australian National Schools Interoperability Program (NSIP), drawing on a corpus of web-based technical and promotional documents and interviews with key actors. It is argued that Australia has a well-developed data infrastructure in schooling that is creating new relations between school systems and commercial vendors in new network markets for data-driven educational technologies.
\end{abstract}

Keywords: data, infrastructure, interoperability, markets, education policy, standards

\section{Introduction}

This paper examines how data standards, and specifically interoperability standards that facilitate data sharing between systems, constitute an infrastructure that frames data as objects of market exchange. The central argument is that markets for data are being made through the generally invisible work of standardisation linked to the growing implementation of data management systems at various scales of schooling, from individual schools to national school systems and the work of international organisations. The procurement of data management systems that follow open standards generates positive network externalities-as more and more organisations implement these software packages, the ability to share and use data, and thus the value of data, increases. Lawn (2013) has observed that what now constitutes schooling as a system, particularly in contexts where there is a drive to make individual schools more autonomous, are the networks of data systems that enable schools to manage, share and use data. In relation to English schooling, Lawn argues that 'the system is now a set of data processes and coded behaviours' (Lawn 2013, 240). While these changes have broad implications for educational governance, the specific aim of this paper is to examine the creation of new market relations between governments and commercial providers that are emerging from the development of data infrastructure in Australian schooling.

Given the centrality of data for the analysis undertaken here, it is important to begin by defining the term. Data first entered English usage in the seventeenth century and refers to what is given for argument (Rosenberg 2013). At this time, the term was used to describe information given in religious texts that was subject to theological debate and did not necessarily imply quantity or numbers. During the eighteenth century, the term was increasingly used to refer to the results of experience or experiment, rather than received knowledge. This shift is the basis of the modern usage, which has consolidated during the twentieth century with the emergence of computing and information technology. Data now commonly refers to numerical data in digital formats.

Data must be distinguished from other related concepts such as information, evidence and fact, in order to give due attention to the processes through which data are made useful and valuable. Kitchin and Dodge (2011) contrast data with capta. While data can be understood as everything that is given, capta describe a subset of data. As data are selectively captured they are organised or given a particular form. Data are what is given, capta are what is selected and information is the form that 
is given to captured data (Galloway 2011). It is through this process that data are framed as usable pieces of information. The capacity to determine how data are captured and formatted can provide substantial power and influence over how data are used and the value that data generate. While the terms 'data' and 'information' will be used interchangeably here, it is important to keep in mind the process of translation involved in capturing data in a specific form.

Large-scale assessments have become an important source of data in schooling. Along with the development and growth of international large-scale assessments since the 1950s, there has also been widespread growth in national testing programs. Sample-based assessments like the US National Assessment of Educational Progress (NAEP) and census-based assessments like Australia's National Assessment Program - Literacy and Numeracy (NAPLAN) are two examples. We have also seen a dramatic proliferation of sub-national and school level standardized testing programs. Educational testing is now quickly moving to online platforms that increase the volume and types of data that are generated. Schools systems also generate large volumes of administrative data, relating to both staff and students, that must be aligned to manage processes such as timetabling.

This rise of data in schooling has played an important role in the restructuring of educational governance. Data are used within school systems and governments to monitor performance and have become the lifeblood of new public management accountability systems that operate by setting targets linked to sanctions and rewards. Anagnostopoulos et al. $(2013,2)$ argue that ' $[t]$ he data that fuel test-based accountability are ... the products of complex assemblages of technology, people, and policies that stretch across and beyond the boundaries of our formal educational systems'. School systems now use commercially provided Student Information Systems (SIS) to integrate and manage multiple types of data across and business intelligence platforms that enable powerful new approaches to data analytics and visualization. These hardware and software platforms are also embedded in wider sets of beliefs, policies, codes and desires that form part of the infrastructure that gives data the power to reshape life in schools. Data infrastructure thus extend beyond the computing systems that are used to capture, store and analyse data (Sellar 2015).

The aim of this paper is to (1) map the development of a national data infrastructure in Australian schooling and (2) examine the role of this infrastructure in making new markets for data-driven education products and services. The paper is divided into five remaining sections. The following section provides background to the analysis by surveying developments in the education technology market and the decades long agenda to develop interoperability standards for school. The theoretical framework, which focuses on concepts of infrastructure, markets and standardisation, is then introduced and is followed by a short methodological discussion. The empirical case of data infrastructure in Australian schooling is analysed in the fourth section, with a focus on the work of the National Schools Interoperability Program (NSIP), followed by a short summative conclusion.

\section{Background}

\section{Education technology markets}

In 2012, Pearson plc $(2012,8)$ predicted in their annual report that 'education will be the biggest growth industry of the $21^{\text {st }}$ century' and it comprises multiple markets of different kinds. The education technology market is a relatively small but increasingly lucrative part of this growing global education industry. In 2014, the US Software and Information Industry Association (SIIA) published a survey that estimated the US education technology market to be worth over $\$ 8.38$ billion (Richards \& Stebbins 2014). This is a modest amount in the context of overall spending on public schooling in the US, which is in the hundreds of billions annually, but it should be seen in the context of its rate of growth. In 2014, the value of the education technology market increased by 
$5.1 \%$ from the previous year and by $11 \%$ since 2010 . Importantly, this valuation only counts software and digital content, not hardware such as computers or other devices, the provision of Internet services and so on. Testing and assessment was the most valuable market category, worth \$2.5 billion and having grown by $57 \%$ over the previous two years, followed by English Language Arts and Reading content, Mathematics content, and online courses, each of which are driven by online testing and assessment. There is increasing demand for systems that integrate data from different sources in useable formats and the report argues that:

[in] the age of big data and formative assessment, companies working to help schools efficiently collect, analyse, and make actionable their student data have a tremendous opportunity. This opportunity includes support not only for basic testing, attendance, and grading information, but also for social networks ... new adaptive learning platforms, and relevant family and community information. (Richards \& Stebbins 2014, 41; emphasis added)

The potential for strong growth in the profitability of the market is being driven by the generation of new kinds and quantities of data and the development of new modes of data analytics. Both testing and assessment and data analysis and integration are identified as key growth areas for the industry in coming years (Richards \& Stebbins 2014).

The SIIA report demonstrates that the market for digital educational data already offers substantial commercial value and is growing quickly as government and non-government schools and jurisdictions procure new information systems. One key challenge to growth is privacy, especially laws and regulations that limit access to and the circulation of student data, and the need for industry to lobby governments to reduce limitations placed on data sharing is emphasized by SIIA. The industry is employing strategies such as partnerships between philanthropies and think tanks to lobby for regulatory changes that would increase data dissemination and transparency. Increasing the interoperability of systems and data sharing is an important enabling condition for market growth. The report makes clear that there is demand in school districts for interoperability between various systems and this demand is driving infrastructure development (Richards \& Stebbins 2014), which is often funded by the state. While this discussion focuses specifically on the US, which has an industry body that publishes market surveys, it reflects broader international trends towards growth in demand from schools and school systems for information systems that can integrate and manage proliferating volumes of educational data.

\section{Data standardization in education}

Various agendas to standardise education data have emerged as the education technology market has expanded over the past two decades. A number of interoperability standards have been developed, including the Schools Interoperability Framework (SIF), 'IMS Global's Learning Tools Interoperability (LTI) standards and the US Department of Defense's Shareable Content Object Reference Model (SCORM). Interoperability standards specify common data models that enable data to be shared between applications and different systems. As Gruber $(1993,200)$ has argued, ' $[k]$ nowledge-based systems pose special requirements for interoperability'. Interoperability enables more efficient transaction of data and increases the usefulness of data because it can be exchanged and used across multiple platforms. There are considerable benefits in standardisation for schools and school systems, including purchasing generic applications that can be integrated into existing systems with lower development costs and fewer risks. The focus in this paper is the implementation of the SIF specification in Australian schooling. 
In February 1999, Microsoft co-founder Bill Gates launched SIF at the US School Administrator's Annual Conference (SIF Association 2012). Gates described the need for school districts to develop 'digital nervous systems' built on data standards that would constitute 'a big step forward for both the educational software industry and schools' (Microsoft Corp. 1999). This initiative was led by Microsoft and supported by 18 other software companies and SIIA. The first specification of the SIF standards was released in November 1999. A more developed specification of the standards was released in 2003, and at this time the US Department of Education joined the development efforts. In 2006, a SIF Association was established in the UK and Australian Ministers of Education agreed to adopt and develop an Australian SIF specification in 2009. In 2015, the Access 4 Learning (A4L) Community was launched as an overarching organisation bringing together SIF associations in North America, the UK and Australia. The A4L community is described as a 'non-profit collaboration composed of schools, districts, local authorities, states, US and International Ministries of Education, software vendors and consultants who collectively address all aspects of learning information management and access to support learning' (www.a4l.org). The rebadging of the SIF community as the A4L community coincided with an expansion of the focus of these SIF organisations beyond data management to enable 'the usage of that data as true learning information for parents, practitioners and learners themselves' (A4L 2015). A4L argues that its standards now constitute 'the most comprehensive data model and mature infrastructure interoperability framework in use globally in education' (A4L 2015).

The Bill and Melinda Gates Foundation has been a strong proponent of data-driven education policies and practices through its K-12 Education (http://dataqualitycampaign.org) and Postsecondary Success programs (http://www.ihep.org/postsecdata). In 2007, the Foundation commissioned a report from The Parthenon Group that reviewed the education data landscape and highlighted the growing market for information management systems and pointed to the commercial opportunities for private vendors (The Parthenon Group 2007). Under the auspices of its Institute for Higher Education Policy, the Gates Foundation is aiming to develop a national postsecondary data infrastructure, including linking up data sets across government departments. While the Gates Foundation has a philanthropic agenda, this cannot be easily disentangled from its promotion of corporate approaches to philanthropic activity, its network of relationships with corporate actors and its political lobbying. The key point here is that the standardisation and joining up of data systems in education is an agenda that has been pursued by key players in the technology industry since the mid 1990s and it continues to gather momentum and political influence.

\section{Conceptual framework: Infrastructure, standards and market making}

Data infrastructure is built on standards. Busch $(2011,111)$ observes that '[p]erhaps the grandest project of the late nineteenth and early twentieth centuries was the attempt to standardize markets and the economy as a whole' and this project has not lost momentum in the twenty-first century. The standardisation of markets is now closely associated with a more recent 'grand project'. MayerSchonberger and Cukier $(2013,96)$ have suggested that ' $[w]$ e are in the midst of a great infrastructure project ... [of] datafication'. The dramatic growth of datafiction-practices that facilitate the translation of various qualities into quantities that can be stored and manipulated in digital formats - has been supported by the creation of information systems that comprise various sensors and inputs, data networks, storage solutions, and software platforms for conducting analysis and representing data in comprehensible and usable formats. These systems underpin modern markets and both datafication and standardization are part of broader social processes of commensuration (Espeland \& Stevens 1998). 
Kitchin and Lauriault $(2015,467)$ provide a definition of data infrastructure as 'a digital means for storing, sharing and consuming data across networked technologies'. The study of information systems as a form of infrastructure benefited from the influential ethnographic work of Susan Leigh Star in the 1990s (e.g. Star 1999; Star \& Ruhleder 1996). Star and Ruhleder (1996) argue that the development of infrastructure requires significant investments of time and money that embed it in other systems in often hidden ways. Infrastructure is commonly understood to take the form of material structures-roads and rails, pipes and wires-and this is certainly the case with the hardware, cables and radio transmitters on which networked technologies now operate. However, drawing from earlier periods of infrastructure studies and the more recent work of Keller Easterling, an expanded concept of infrastructure will be employed in the analysis that follows.

Easterling (2014) defines infrastructure in spatial terms as active form that produces urban spaces. Infrastructure extends beyond material structures to include other things like software, standards and ideologies. Bowker et al. (2012, 99), drawing from Star and Ruhleder (1996), describe infrastructure as 'a fundamentally relational concept; it emerges for people in practice, connected to activities and structures. It consists of both static and dynamic elements, each equally important to ensure a functional system'. Infrastructure can be understood, from this perspective, as a dynamic relational form that generates the static objects which provide the material traces of a functional system.

Easterling $(2014,13)$ argues that ' $[i]$ nfrastructure space has become a medium of information. The information resides in invisible, powerful activities that determine how objects and content are organized and circulated. Infrastructure space, with the power and currency of software, is an operating system'. The analogy with an operating system underlines the active nature of infrastructure. For example, computers and cables are object forms, whereas standards and codes are active forms. Easterling emphasises active forms, arguing that '[i]nfrastructure space is a form, but not like a building is a form; it is an updating platform unfolding in time to handle new circumstances' (14). Data infrastructure can thus be understood as an active and changing platform for storing, sharing and consuming data across networked technologies. This definition emphasises the issue of interoperability; that is, the capacity for the platform to operate across different material supports (local or virtual machines, for example) and to share data between different systems. In other words, '[t]he shared standards and ideas that control everything from technical objects to management styles also constitute an infrastructure' (Easterling 2014, 11).

The development of data infrastructure involves the specification of standards that are part of its active form. Standardisation helps to frame and stabilize the various objects or goods that are exchanged in markets. Following Callon (1998), markets are understood as devices that coordinate the activities of calculating agencies. These agencies are more than an individual person and include 'the material and devices ... that give his or her actions a shape' (21). Neither the market nor homo economicus preexist the tools and social relations that bring these entities into being as a mutually constitutive process and organization of relations between agencies. These tools include accountancy practices, economic rationalities and various measurement tools, as well as standards that help to disentangle and frame objects of market exchange.

The emergence of calculative agencies requires framing. Callon $(1998,17)$ argues that framing 'allows for the definition of objects, goods and merchandise which are perfectly identifiable ... it is owing to this framing that the market can exist and that distinct agents and distinct goods can be brought into play'. Caliskan and Callon (2010) argue that such '[d]isentanglement is more stable ... when a commodity has undergone specific processes of standardization that transform it into an entity described in both abstract and precise terms, certified and guaranteed by a series of textual 
and material devices' (Caliskan \& Callon 2010, 7-8). From this perspective, markets are continually performed through processes of disentanglement and framing. The state plays an essential role in the constitution of markets through these processes by, among other functions, funding infrastructure, establishing regulatory frameworks and sponsoring standard-setting forums, as will be shown in the case that follows. Standards play an important role in framing goods and the standardisation of quantities, price and currency are the very conditions that 'make modern markets possible' (Busch 2011, 167; original emphasis).

Interoperability standards specify models that frame data as distinct objects (e.g. a student data record) that can be combined, reused and shared. Data, understood as what is given, do not have inherently clear boundaries or commercial value. Even when captured as information in specific formats, data may not be become valuable or exchangeable. Consider, for example, attendance records that schools have long kept in idiosyncratic formats and which may serve local administrative functions but do not have any commercial value. However, the value of data can increase dramatically once it is standardised to enable exchange and reuse in new contexts. Kitchin and Lauriault (2015) explain:

Small data gain value and utility when made accessible for reuse and are combined with other datasets. As a consequence, much effort is being directed at building such infrastructures and in trying to harmonize small data, with respect to data standards, formats, metadata and documentation, to ensure their compatibility with systems, maximize discoverability, and facilitate the linking together of datasets. (473)

Markets for data management emerge with standardisation that enables the linking up of systems, and the creation of new sources of value from data. Lycett $(2013,381)$ argues that the ' $3 \mathrm{Vs}$ ' model used to define big data-volume, velocity and variety-should be augmented by a fourth ' $V$ ': value. Standardisation can be understood as a central aspect of the value creation process, enabling 'liquification' so that 'information can be easily manipulated and moved around (given a suitable infrastructure), allowing resources ... that were closely linked physically to be unbundled and 'rebundled' - in ways that may have traditionally been difficult, overly time consuming or expensive' (382).

For example, Robertson and Komljenovic (2016) have shown how Linkedln has created new datadriven markets by using information provided by its users, including a large base of universities who encourage staff, students and alumni to subscribe to the service. The data entered by users into their LinkedIn profile was likely already available in other forms and locations (e.g. university staff webpages), but can be 'liquified', joined up and reused when formatted according to the data models that underpin the LinkedIn platform. The growth of data infrastructure and interoperability thus creates potential to generate new value from data, which is precisely what is now happening in school systems around the world.

\section{Methodology}

The analysis that follows draws on data from a multinational comparative research study that is mapping and comparing data generation and usage in schools and school systems in Australia, Canada, the US and Japan. ${ }^{1}$ Our methodological approach draws on the emergent field of infrastructure studies, as well as the literatures on mobilities in sociology (Urry 2007) and network

\footnotetext{
${ }^{1}$ The project is titled Data infrastructure, mobilities and network governance in education and is funded by the Australian Research Council Discovery Project scheme (DP150102098). The Chief Investigators are Bob Lingard, Kalervo N. Gulson, Sam Sellar and Keita Takayama. The Partner Investigators are Christopher Lubienski and P. Taylor Webb.
} 
governance in education (Ball \& Junemann 2012). The project has employed multi-modal ethnographic methods to map flows and spaces of data, from their production to sites of enactment, use and implementation. Data collection for the project has so far involved conducting more than 40 semi-structured interviews with staff in schools, local and regional school systems (e.g. school boards in North America or state education systems in Australia), and national government departments, as well as extensive analysis of web-based documents.

The case examined here is that of the development of interoperability standards in Australian schooling under the auspices of NSIP. It can be argued that, as a result of the work completed by NSIP and the national commitment to the project, Australian schooling now has the most developed national data infrastructure in the world. The selection of NSIP thus fits the criteria for a revelatory single case study (Yin 2009). The data set for the analysis that follows is a corpus of technical and promotional documentation relating to SIF, NSIP and the data systems of Australian state education departments. The broader set of project interviews provide a background to the analysis and a subset of four interviews with Australian policy makers and technical staff were used to help identify relevant documents and check interpretations of technical issues.

\section{Data infrastructure in Australian schools}

This case study examines (1) the development and standardisation of data systems in Australian schooling and (2) associated creation of opportunities for commercial provision of data-driven products and services to schools and systems. NSIP was established in 2010 to support the interoperability of information systems used by government and non-government schools and school systems across Australia. This followed the endorsement of an Australian SIF specification by Australian Ministers of Education in 2009. NSIP is a joint initiative of Federal, State and Territory Ministers for Education and operates under the auspices of the Council of Australian Governments Education Council (SCSEEC) and the Australian Education Senior Officials Committee (AESOC). The Program is supported by each of the State and Territory school systems and the Australian Government, as well as the Catholic and Independent school sectors. Its work is overseen by a steering group that includes Chief Information Officers $(\mathrm{CIO})$ from each State and Territory education system. This work includes support for projects that involve: '[s]tandards based system integration'; '[d]ata sharing between organisations and jurisdictions; '[r]euse of infrastructure'; and '[d]ata aggregation and synchronisation' (http://www.nsip.edu.au/services-and-projects). The day-to-day technical work of NSIP is undertaken by a relatively small team of approximately ten staff.

NSIP is closely aligned with the Australian SIF Association (SIF AU), which currently has 38 members. The membership comprises: 13 governments and government bodies; 9 Catholic and independent school bodies; and 16 commercial vendors. The main product categories offered by these vendors are information management systems, including Student Information Systems (SIS) and timetabling software, but there is a diverse array of companies including app developers and providers of medical simulation software. In 2015-2016, representatives from two of these vendors sat on the Australian SIF Association Management Board and there were five vendor representatives on the Technical Board. The NSIP website lists more than a dozen vendors who have SIF compliant SIS projects at various stages of development. One key service provided by NSIP is an 'industry forum on technical and interoperability matters for educators and solution providers'

(http://www.nsip.edu.au/services-and-projects) that provides a new kind of interface between schools and commercial organisations.

One of the rationales for ensuring the interoperability of information systems across Australian school systems is the growing federal presence in schooling, which since 2007 has seen the introduction of national curriculum, national literacy and numeracy testing and national teacher 
standards (Lingard 2010). Proponents of national curriculum argue that students should be able to move between State and Territory school systems without missing aspects of the curriculum. A natural extension of this argument is that student records should also be transferable between systems in order to track attendance, particularly for mobile student groups such as Indigenous students living in remote areas. Indeed, one of the pilot projects supported by NSIP used SIF standards to develop a system for sharing data between the Western Australia, South Australia and Northern Territory school systems (SIF AU, n.d.). This project used a unique student identifier and a central application, or agent, to aggregate student data from three jurisdictions and update it on a near real-time basis. Two of the key findings from this project were that to 'continue to serve the needs of the Australian education sector, the SIF AU specification requires ongoing development, including regular engagement with local industry and SIF vendors' and '[V]endors need access to infrastructure within jurisdictions' (SIF AU, n.d.).

State and Territory education departments are expected to procure SIF compliant SIS when replacing current systems and NSIP has also overseen the development of a Student Information System Baseline Profile (SPB), which facilitates data exchange between applications and organisations. The SPB uses the SIF data model to specify common data definitions. The Australian SIF Association explains that

[t]he SBP is a breakthrough agreement that defines the relationship between Students, Parents, Teachers, Schools and Classes in a digital machine readable format. It will facilitate the next generation of online services being linked securely into a school's systems - by reducing the complexity, cost for schools and increasing the ease for vendors'. (SIF Association AU, n.d.; emphasis added)

The SPB was developed with a group of nine SIF vendors and demonstrates the commercial imperative for interoperability standards: reducing the costs for vendors associated with (1) discovering idiosyncratic data formats used by different jurisdictions and (2) developing new applications from the ground up for each customer.

As Pollock and Williams (2009) argue, managing the relationship between users and suppliers is an important element of growing markets for software packages. NSIP constitutes an example of what Pollock and Williams call 'management by community', which enables a transition from providing particular solutions for individual customers to developing standardised generic technologies for a wider customer base whose requirements are carefully shaped by vendors. The forum provided by NSIP enables 'suppliers and users of software packages [to] constantly work towards a pragmatic solution of the tension between the generic and the particular' (p. 175). One concrete mechanism for enabling this work is NSIP's Hub Integration Testing Service (HITS).

HITS is an interface that enables vendors to test whether their software will integrate successfully with a particular jurisdiction and it fulfills the requirement identified in pilot projects for vendors to have access to jurisdictional infrastructure. The NSIP website explains that:

HITS allows jurisdiction and vendor teams to achieve a level of technical assurance that interoperability will succeed, without having to undertake this discovery process as part of a formal project. HITS itself is a hosted service that allows data interactions and which presents SIF and other suitable endpoints to allow developers to test their system interactions. HITS comes with sample client applications, full developer and 
administrator documentation and a rich set of credible synthetic school data to make testing and development as meaningful as possible. (http://www.nsip.edu.au/hits-hubintegration-testing-service)

Put simply, HITS enables vendors to test their software with synthetic data that accurately reflects the data structures of a particular school or system. The HITS technology may enable vendors to discover information and develop products before users see a need for them. The NSIP website explains that:

[i]n the next 3-5 years the CIOs of all education jurisdictions see a significant shift in their role in the market. This shift will be for education jurisdictions to act as information hubs, exposing student, staff and school data to trusted third party developers, with the expectation that the market will provide products of value to schools that make use of that information. (http://www.nsip.edu.au/hits-hubintegration-testing-service)

The CIOs who constitute the Steering Group for NSIP have in mind a model where school systems provide synthetic data to vendors as a resource for product development outside of specific contracts for products or services. Testing to ensure that a particular software package is interoperable can be undertaken before responding to a request for tender or to develop commercial off-the-shelf (COTS) products or services that can be marketed to, and adapted for, a broad potential customer base.

Prior to the work of NSIP, a school system purchasing a Student Information System (SIS) would have needed to cover the costs of the supplier discovering their data structures and designing a product that functioned in relation to these structures, within the timeframes and budget of the project. If the same school system used SIF compliant data structures, then the provider would not need to dedicate the same amount of resources to designing bespoke applications. Moreover, the provider can reuse the same applications or software 'building blocks' in products for other SIF-compliant school systems, thus widening the market for their products. The reduced development costs can be passed on to consumers, increasing the competitiveness of the products in the marketplace.

The case of NSIP shows how the development and adoption of interoperability standards can be understood as a market making process with three important dimensions. First, standardisation reduces the time and cost of product development and enables a shift from particular to generic solutions. Second, the forums required to enact standardisation are a state-sponsored space in which suppliers can shape the needs of users, creating demand for products and services that they can profitably provide. Third, the tools for enabling interoperability expose data to vendors and provide them with new resources for product development. In this latter case, we can clearly see how joining up data sets and 'liquifying' data creates new sources of value for commercial organisations.

An important question that remains to be answered is why Gates initially championed SIF as an open standard, not a proprietary one. The answer to this question requires a complex understanding of the phenomenon of 'lock-in'. As Callon (1998) argues, lock-in is not simply a deteriorated form of open market in which consumers are captured by particular companies or products. Instead, by limiting options, lock-in enables calculation and thus helps to constitute and organize markets. 
Once the work of standardization (at least partial) of calculating tools is well on its way, each agency is in a position not only to calculate her decision but also, by construction, to include, at least partially, in her calculations the calculations of the other agencies.

This integration, which is the material side of what we call anticipation, is far easier when, during the process of market organization, a calculative agency manages to impose directly her instruments and mode of calculation ... (50)

While the imposition of proprietary instruments is a favoured lock-in strategy of organisations like Microsoft and Apple, jumpstarting the work of standardization is a necessary precursor.

In the initial stages of organizing and constituting markets it can be advantageous to join communal efforts to develop open standards. Education technology markets are currently in these early stages of being organized and are network markets in which the value of a product depends on how widely it is used (Shapiro and Varian 1999). Shapiro and Varian (1999) explain that

[t]echnologies subject to strong network effects tend to exhibit long lead times followed by explosive growth. The pattern results from positive feedback: as the installed base of users grows, more and more users find adoption worthwhile.

Eventually, the product achieves critical mass and takes over the market. (p. 13)

The market for information management systems in education has been in its long lead time since SIF was initially specified in 1999. In these circumstances, the development of open standards is a good strategy for growing the total value of the market and potentially sparking explosive growth of positive externalities as the network of users reaches a critical point. This can be a good strategy even for large players like Microsoft, who can compete in areas such as branding and marketing when the market makes the shift from particular to generic solutions (Shapiro and Varian 1999). From this perspective, the work of NSIP and the development of data infrastructure in Australian schooling can be understood as a strategy to make network markets for data-driven products and services, with benefits for both customers and suppliers.

\section{Conclusion}

This paper has examined how the development and adoption of interoperability standards for educational data in Australia is making markets for data-driven products and services. These markets are currently somewhere between the end of a long lead time and the beginning of what will likely be an explosion in demand. The development of open standards such as SIF has helped an alliance of corporate interests to grow the value of the overall pie in order to grow the value of their market segment. Whether standards remain open, or whether some companies seek to fork these agendas into proprietary specifications, remains to be seen.

Standardisation and the transition towards more generic software packages reduces the time and cost of product development. The forums that have been established to advance the agenda of standardisation provide a space in which commercial actors shape the demands of users, which in this case are often governments, thus creating the demand for products and services that can be profitably provided. This is an important vector of 'soft power' (Nye 2008). Finally, concrete mechanisms for enabling interoperability are now providing commercial actors with synthetic data generated within and by public institutions as a resource for product development. In some cases in the US, contracts between school systems and vendors go so far as specifying that the supplier owns the actual data generated by the school system and simply provides the user with reports. States are 
helping to develop this data infrastructure and access to this infrastructure that enables joining up and liquification of data is providing education technology vendors with new sources of value.

Participation in the development and use of these infrastructures can thus be seen as an important source of both political power and commercial profit. As Easterling argues, '[c]ontemporary infrastructure space is the secret weapon of the most powerful people in the world precisely because it orchestrates activities that can remain unstated but are nevertheless consequential' ( $p$. 15). We can see the obvious benefit that influential economic and political actors such as Microsoft and the Gates Foundation can gain from participation in the development of standards and data infrastructure in schooling.

While the corporate players involved in the Australian case are much less influential, the standards setting forum provided by NSIP can still be seen as a site of what Easterling calls 'extrastatecraft': 'the often undisclosed activities outside of, in addition to, and sometimes in partnership with statecraft' (p. 15). The 'management by community' that NSIP enables for software vendors and the provision of tools such as HITS shift the balance between the procurement of software packages by school jurisdictions and the shaping of demand by corporate actors (Pollock \& Williams 2009). The case of NSIP demonstrates clearly how new forms of network governance and network markets are emerging in schooling through standardisation processes that are often hidden and conducted in a language of opaque technical jargon. However, the obscurity of this work is the source of its influence and demands careful scrutiny. 


\section{References}

A4L. 2015. Introducing the Access 4 Learning Community - The SIF Association Matures to Address Not Only Data Management but Data Usage for Learning. Retrieved from https://www.sifassociation.org/NewsRoom/Press\%20Releases/Introducing\%20the\%20Acces s\%204\%20Learning\%20Community.pdf

Anagnastopolous, D., Rutledge, S.A., \& Jacobsen, R. (Eds.) 2013. The infrastructure of accountability: data use and the transformation of American education. Harvard Education Press: Cambridge, MA.

Ball, S.J., \& Junemann, C. 2012. Networks, new governance and education. Bristol: The Policy Press. Bowker, G.C., Baker, K., Millerand, F. \& Ribes, D. 2010. Toward information infrastructure studies: Ways of knowing in a networked environment. In J. Husinger, L. Klastrup \& M. M. Allen (Eds.), International handbook of internet research (pp. 97-117). Springer: Dordrecht \& London.

Busch, L. (2011). Standards: Recipes for reality. Cambridge, MA \& London: The MIT Press.

Çalışkan, K., \& Callon, M. 2010. Economization, part 2: A research programme for the study of markets. Economy and Society 39 (1): 1-32.

Callon, M. 1998. Introduction: the embeddedness of economic markets in economics. The Sociological Review 46 (S1): 1-57.

Easterling, K. (2014). Extrastatecraft: The Power of Infrastructure Space. New York: Verso Books.

Espeland, W. N., \& Stevens, M. L. 1998. Commensuration as a social process. Annual Review of Sociology 24: 313-343.

Galloway, A. (2011). Are some things unrepresentable? Theory, Culture \& Society, 28(7-8), 85-102.

Gruber, T. 1993. A translation approach to portable ontology specifications. Knowledge Acquisition 5: $199-220$.

Kitchin, R., \& Dodge, M. 2011. Code/space: Software and everyday life. Cambridgbe, MA: MIT Press.

Kitchin, R. \& Lauriault, T.P. 2015. Small data in the era of big data. GeoJournal 80 (4): 463-475.

Lawn, M. (2013). Introduction: The Rise of Data in Education, In M. Lawn (Ed.), The Rise of Data in Education Systems: Collection, Visualisation and Use. Oxford: Symposium.

Lingard, B. (2010). Policy borrowing, policy learning: testing times in Australian schooling. Critical Studies in Education 51 (2): 129-147.

Lycett, M. (2013). 'Datafication': making sense of (big) data in a complex world. European Journal of Information Systems 22: 381-386.

Nye, J. S. 2008. Public Diplomacy and Soft Power. The ANNALS of the American Academy of Political and Social Science 616 (1): 94-109.

Pearson plc. 2012. Annual report and accounts 2012. Retrieved from http://www.pearson.com/content/dam/pearsoncorporate/files/cosec/2013/15939_Pearson AR12.pdf.

Pollock, N. \& Williams, R. 2009. Software and oirganisations: The biography of the enterprise-wide system or how SAP conquered the world. London \& New York: Routledge.

Mayer-Schonberger, V., \& Cukier, K.N. 2013. Big data: a revolution that will transform how we live, work, and think. Boston: Houghton Mifflin Harcourt.

Microsoft Corp. 1999. Schools Interoperability Framework Initiative Releases First Working Specification Following Successful School Pilots. Retrieved from https://news.microsoft.com/1999/11/10/schools-interoperability-framework-initiativereleases-first-working-specification-following-successful-schoolpilots/\#sm.0000yj2my0lc0dswwc41t8rob1yxg

Richards, J. \& Stebbins, L. 2014. 2014 U.S. Education Technology Industry Market: PreK-12. Washington, D.C.: Software \& Information Industry Association.

Rosenberg, D. 2013. Data before the fact. In L. Gitelman (Ed.), "Raw data" is an oxymoron (pp. 1540). Massachusetts, MN: The MIT Press. 
Robertson, S., \& Komljenovic, J. 2016. Unbundling the University and Making Higher Education Markets. In G. Steiner-Khamsi, C. Lubienski \& A. Verger (Eds.), World yearbook of education 2016: The global education industry (pp. 211-227). New York: Routledge.

Sellar, S. 2015. Data Infrastructure: A Review of Expanding Accountability Systems and Large-Scale Assessments in Education. Discourse: Studies in the Cultural Politics of Education 36 (5): 765777.

Shapiro, C. \& Varian, H. 1999. Information rules: A strategic guide to the network economy. Boston, MA: Harvard Business School Press.

SIF Association. 2012. The SIF Association celebrates 15 years! Retrieved from https://www.sifassociation.org/NewsRoom/Press\%20Releases/SIF\%20Association\%20Celebr ates\%2015\%20Years.pdf

SIF Association Australia. n.d. Tri-Borders: Supporting students across SA, NT and WA. Retrieved from http://www.nsip.edu.au/sites/nsip.edu.au/files/Pilot\%202.1\%20Tri-Borders.pdf

Star, S.L. 1999. The ethnography of infrastructure. American Behavioural Scientist 43 (3): 377-391.

Star, S., \& Ruhleder, K. 1996. Steps toward an ecology of infrastructure: design and access for large information spaces. Information Systems Research 7 (1): 111-134.

The Parthenon Group. 2007. Landscape Review: Education Data. Retrieved from https://docs.gatesfoundation.org/documents/landscape-review-education-data.pdf

Urry, J. 2007. Mobilities. Cambridge \& Malden, MA.: Polity Press.

Yin, R. 2009. Case study research: Design and methods ( $4^{\text {th }}$ edition). Thousand Oaks, California: Sage.

'The acronym stands for Systems Interoperability Framework in the United Kingdom. 